\title{
Spectrum of Diseases/conditions Exhibiting Hemostatic Abnormalities in Patients Admitted to a Medical Intensive Care Unit of a Tertiary Care Hospital
}

\author{
Girish Chandrakant Rajadhyaksha, Ameena Meah \\ Department of Medicine, Topiwala National Medical College \& B.Y.L. Nair Ch Hospital, Mumbai, Maharashtra, India
}

Abstract

Background and Aims: In a medical intensive care unit (MICU), many patients develop hemostatic abnormalities, ranging from abnormal clotting tests to frank bleeding. The aim of this study was to assess the etiology of diseases that present with bleeding, its common bleeding manifestations, incidence, MICU stay, mortality, and transfusion requirements in an Indian setup and also to assess if the Acute Physiology and Chronic Health Evaluation II (APACHE II) score can be used as a predictor for blood transfusion requirements. Materials and Methods: Between July 2013 and August 2014, 200 patients with clinically significant bleeding admitted in the MICU were prospectively evaluated. Detailed history, examination, laboratory investigations, APACHE II score, and requirement of blood products were also noted. The endpoints were discharge or death. Results: The spectrum of diseases that presented with bleeding was 47 patients with malaria (23.5\%) followed by 36 acute undifferentiated febrile illness (18.0\%), 33 dengue (16.5\%), 30 leptospirosis (15.0\%), 31 acute fulminant hepatitis $(15.5 \%)$, 14 sepsis $(7.0 \%)$, and the rest nine miscellaneous causes. The most common bleeding manifestation observed was hematuria in $62 / 200(31 \%)$. Among the patients studied, 126 expired (63\%) and 74 survived (37\%). Of the 200 patients, 48/200 (24\%) received packed cells, 78/200 (39\%) fresh frozen plasma, and 82/200 (41\%) platelets. Conclusions: Tropical diseases formed the majority of admissions with bleeding manifestations. Thrombocytopenia is an important marker to predict mortality and also has a significant association with MICU stay. APACHE II score was found to be a good predictor of blood transfusion requirements.

Keywords: Acute Physiology and Chronic Health Evaluation II score, bleeding, intensive care unit, transfusion, tropical diseases

\section{INTRODUCTION}

Hemostasis - "hemo" is derived from New Latin which means blood; "stasis" is derived from Greek which means standing still. ${ }^{[1]}$ Three hemostatic systems: Platelets, intact vasculature, and soluble clotting factors, interact effectively to protect humans from clinically significant bleeding. Significant bleeding is rare until two of the three systems malfunction, and then the magnitude of each failure often must be significant. ${ }^{[2]}$ There is a spectrum of diseases or conditions that we come across in a medical intensive care unit (MICU) that present with clinical or laboratory evidence of hemostatic abnormality. A clinician is often stressed when bleeding and coagulation tests are alarmingly on the rise. At times, apprehension may arise from a sense of responsibility for bleeding following procedures or perhaps the fact that hemorrhage is often visible externally. ${ }^{[3]}$

\begin{tabular}{|l|l|}
\hline \multicolumn{3}{c|}{ Access this article online } \\
\hline Quick Response Code: & Website: \\
& www.ijccm.org \\
& \\
\end{tabular}

The information gained from a careful history-taking, physical examination, laboratory confirmation of the hemostatic abnormalities, and finally the correct interpretation of these results help in the accurate diagnosis and treatment of these patients admitted in the MICU. These patients are major consumers of blood products, yet their incidence and cause have not been studied in detail. Although studies regarding the proportion of patients in MICU with bleeding, their etiology and prognosis are reported from the western world; ${ }^{[4]}$ there is a paucity of data from Indian centers. Having met with limited

Address for correspondence: Dr. Ameena Meah, 104, Department of Medicine, College Building, Topiwala National Medical College \& B.Y.L Nair Ch Hospital, Dr. A.L. Nair Road, Mumbai - 400 008, Maharashtra, India. E-mail: ameena.meah@gmail.com

This is an open access journal, and articles are distributed under the terms of the Creative Commons Attribution-NonCommercial-ShareAlike 4.0 License, which allows others to remix, tweak, and build upon the work non-commercially, as long as appropriate credit is given and the new creations are licensed under the identical terms.

For reprints contact: reprints@medknow.com

How to cite this article: Rajadhyaksha GC, Meah A. Spectrum of diseases/ conditions exhibiting hemostatic abnormalities in patients admitted to a medical intensive care unit of a tertiary care hospital. Indian J Crit Care Med 2018;22:711-7. 
research in this field, we undertook this study hoping to gauge the intensity of this problem. Burdened by the ever-growing demand of blood transfusion products, it is necessary to develop means to predict blood transfusion requirements for each individual so as to be well prepared in times of emergency.

The study was aimed to understand the etiology, incidence, MICU stay, mortality, and bleeding manifestations seen in patients admitted with hemostatic abnormalities in the MICU and to study the transfusion requirements in them and also to assess any association between the Acute Physiology and Chronic Health Evaluation (APACHE) II score at admission in patients with bleeding and blood transfusion requirements.

\section{Materials and Methods}

It is a single-center prospective cohort study carried out from July 2013 to August 2014 in the MICU of a tertiary care hospital in Mumbai, after receiving approval from the Institutional Ethics Committee. Consecutive male and female (pregnant and nonpregnant) patients $\geq 18$ years admitted in the MICU, with clinically evident bleeding unexplained by local factors, with one of the following: prothrombin time/ international normalized ratio (PT/INR) $\geq 1.5$ times the control or activated partial thromboplastin time (aPTT) $\geq 40 \mathrm{~s}$ or platelet count $<100,000 /$ cumm, were enrolled in the study. The exclusion criteria were patients with a known bleeding and coagulation disorder (based on history), patients with current use of anticoagulants (heparin/warfarin), and patients who denied a formal consent. A total of 200 patients were finally enrolled after a valid consent was taken from the patient or his/her legally accepted representative.

Case record forms were used to note down the name, age, sex, occupation, and days of MICU stay. Detailed history-taking with special emphasis on bleeding manifestations, drug history, and any previous similar episodes of bleeding were noted. Evaluation of pulse rate, respiratory rate, temperature, blood pressure, and evidence of clinically significant bleeding was done. A complete general and systemic examination was carried out. Need for mechanical ventilation, APACHE II score, and Glasgow coma scale was also noted down. Table 1 lists the case definitions for the diseases that were included in the study.

Laboratory investigations included complete blood count, renal function tests, liver function tests, and arterial blood gas analysis, and coagulation tests included were PT/ INR, aPTT, bleeding time, and clotting time. In patients who exhibited severe thrombocytopenia (platelet $<50,000 /$ cumm), deranged coagulation parameters (INR $\geq 1.5$ and aPTT $>40 \mathrm{~s}$ ), and required one of the blood products; d-dimer level, fibrin degradation products level, and fibrinogen level were carried out to evaluate for disseminated intravascular coagulation (DIC). Other radiological and blood investigations were done as per the discretion of the MICU in-charge for arriving at the primary diagnosis.

The patient was regularly followed up with regard to their clinical developments, laboratory parameters, and blood product requirements. Every patient's treatment was individualized, and they were treated as per the existing practices without disturbing their routine protocol as per the sole discretion of the treating MICU in-charge. The primary endpoint was discharge or death.

\section{Statistical analysis}

Quantitative data were presented as mean and standard deviation and compared by Student's $t$-test. Qualitative data were presented as frequency and percentage and compared by Chi-square test. Efficacy of parameters such as APACHE II score as screening test to predict the transfusion requirements was done using receiver operating characteristics (ROC). $P<0.05$ was considered statistically significant.

\section{REsULTS}

There were 1515 admissions in the MICU during the study period, and 200 consecutive and consenting patients were enrolled in the study who presented with clinically evident bleeding. The results are presented in Tables 2-7.

\section{Table 1: Case definitions of diseases that were followed in the study for inclusion}

\begin{tabular}{ll}
\hline Diseases /Conditions & Investigations done/definition used \\
\hline Malaria & Peripheral smear positive for Plasmodium species (vivax/falciparum) or rapid malaria antigen test \\
Dengue & Positive dengue IgM antibody test or dengue NS1Ag or dengue PCR \\
Leptospirosis & Positive Leptospira IgM antibody test or Leptospira PCR test \\
Snake bite & As per history and clinical features \\
Acute fulminant hepatitis & Defined as a severe liver injury, potentially reversible in nature and with onset of hepatic encephalopathy \\
& within 8 weeks of the first symptoms in the absence of preexisting liver disease ${ }^{[5]}$ \\
& Positive IgM antibody test for hepatitis A, hepatitis E and hepatitis C \\
Sepsis & In case of hepatitis B, HbsAg-positive status and HBV DNA levels \\
Leukemia & Sepsis is defined as a SIRS in the presence of, or as a result of, suspected or proven infection ${ }^{[6]}$ \\
Idiopathic thrombocytopenic purpura & Bone marrow biopsy and immunophenotyping \\
AUFI & Bone marrow biopsy normal and raised levels of immature platelet fraction \\
\hline PCR: Polymorim & Defined as fever of two weeks or shorter in duration and lack localizable or organ-specific clinical features ${ }^{[7]}$ \\
\hline
\end{tabular}

PCR: Polymerase chain reaction; IgM: Immunoglobulin; SIRS: Systemic inflammatory response syndrome; HBV: Hepatitis B virus; AUFI: Acute undifferentiated febrile illness; HbsAg: Hepatitis B virus surface antigen 


\begin{tabular}{lc}
\hline \multicolumn{2}{l}{ Table 2: Demographic and clinical parameters of } \\
200 patients admitted in medical intensive care unit with \\
clinically significant bleeding \\
\hline Parameters & Values \\
\hline Age (years) \pm SD & $33.7 \pm 14.809$ \\
Sex: Male ( $n)$ & 122 \\
Female, $n$ (\%) & 78 \\
Pregnant & $17(21.9)$ \\
Postpartum & $12(15.38)$ \\
Nonpregnant & $49(62.82)$ \\
Highest MICU stay (days) & 8 \\
Mechanical ventilation: Yes/no ( $n)$ & $107 / 93$ \\
Clinical examination findings, Mean \pm SD & \\
Heart rate & $102.9 \pm 15.01$ \\
Respiratory rate & $29.37 \pm 9.54$ \\
Systolic BP (mmHg) & $104.15 \pm 24.72$ \\
Diastolic BP (mmHg) & $66.9 \pm 13.42$ \\
Mean arterial pressure & $76.12 \pm 17.29$ \\
GCS & $13.44 \pm 2.37$ \\
APACHE II score & $13.09 \pm 7.19$ \\
Survivors/expired, $n$ (\%) & $74(37) / 126(63)$ \\
\hline BP: Blood pressure; GCS: Glasgow coma scale; MICU: Medical \\
intensive care unit; SD: Standard deviation \\
\end{tabular}

Table 3: Laboratory parameters of 200 patients admitted in the medical intensive care unit with clinically significant bleeding

\begin{tabular}{lc}
\hline & Mean \pm SD \\
\hline Hemoglobin (g \%) & $9.90 \pm 2.52$ \\
Hematocrit (\%) & $28.49 \pm 8.16$ \\
White blood count (cumm) & $12800.9 \pm 9089.52$ \\
Platelet (cumm) & $74357.5 \pm 80314.9$ \\
PT (s) & $22.4 \pm 9.36$ \\
INR & $2.39 \pm 3.71$ \\
aPTT (s) & $39.58 \pm 11.30$ \\
Bleeding time (min) & $3.47 \pm 1.20$ \\
Clotting time (min) & $6.461 \pm 1.56$ \\
Creatinine (mg/dl) & $2.51 \pm 2.12$ \\
\hline aPTT: Activated partial thromboplastin time; INR: International \\
normalized ratio; SD: Standard deviation; PT: Prothrombin time
\end{tabular}

\section{Discussion}

Bleeding in the MICU is perceived to be an important problem, yet few studies have addressed its clinical impact. Patients with clinically evident bleeding formed $13.2 \%$ of the admissions, i.e., 200/1515. Our results were concordant to the study done by Chakraverty et al. at Oxford-Radcliffe Hospital wherein consecutive admissions were studied to determine the incidence and cause of coagulation disturbances. There were 235 admissions in the ICU over a period of 6 months; 148 male (62.97\%) and 87 female (37.03\%) patients were enrolled. Of the 235 patients who were studied, 32 patients $(13.2 \%)$ were identified as having a clinical coagulopathy defined as bleeding unexplained by local/surgical factors. ${ }^{[4]}$
The mean age of patients in our study was 33.7 years (range 18-80 years); this was not found to be concordant to the study done by Chakraverty et al. and Arnold et al. where the mean age was 56.5 and 63.3 years, respectively. ${ }^{[4,8]}$

Tropical diseases dominated the index study as shown in Table 4. The Indian subcontinent has a heavy monsoon which makes it prone for tropical diseases to flourish. Overcrowding, poverty, illiteracy, and ignorance often lead to a greater spread and prevent the masses from seeking early treatment at the initiation of the symptoms. Due to a delay in transfer to our tertiary care center, most of them presented with complications of the disease. Table 8 shows a comparison between our study and the studies of Chakraverty et al. and Arnold et al. with respect to the spectrum of diseases that presented with the hemostatic abnormalities in the MICU. ${ }^{[4,8]}$

The most common bleeding manifestation observed was hematuria seen in 62 patients (31\%) closely followed by gastrointestinal bleeding in 60 patients (30\%) in the MICU. Gastrointestinal bleeding was a sum of bleeding gums, melena, per rectum bleeding, and hematemesis. Hematuria was the most common bleeding manifestation in $20 / 31$ patients of acute fulminant hepatitis. Arnold et al. and Chakraverty et al. found gastrointestinal bleeding to be predominant. ${ }^{[4,8]}$

The bleeding time was $\leq 6 \mathrm{~min}$ in $95.5 \%$ of patients and $\leq 10 \mathrm{~min}$ in $97.5 \%$ of the patients. Bleeding time testing has largely been abandoned in the MICU because it is difficult to perform, labor-intensive, and a poor predictor of bleeding in the clinical setting. ${ }^{[3]}$ The clotting time was $\leq 10 \mathrm{~min}$ in $195 / 200$ patients and $>10$ min in 5/200.

Conventionally, thrombocytopenia has been defined as a platelet count of $<150,000 /$ cumm, but in critically ill patients, a threshold of $<100,000 /$ cumm has been suggested, ${ }^{[9]}$ due to the relatively high incidence and lack of significant bleeding with counts between $100,000 /$ cumm and $150,000 /$ cumm. ${ }^{[2]}$ Thrombocytopenia is the most common coagulation problem in the MICU, with an incidence of $15 \%-60 \%$ depending on the definition used, population evaluated, and period of MICU stay studied. ${ }^{[10,11]}$ Thrombocytopenia is a common cause of bleeding in the ICU setting. The highest incidence is seen in patients with severe sepsis. ${ }^{[11,12]}$

In our study, thrombocytopenia was seen in 161/200 (80.5\%) patients, of which 121 (63.33\%) expired and 59 (36.64\%) survived. The $P<0.05$ clearly states that thrombocytopenia is an important marker that is predictive of mortality. Severe thrombocytopenia (platelet count $<50,000 /$ cumm) was seen in 111/161 patients (68.94\%), of which $41(36.9 \%)$ survived and 70 (63.1\%) expired. Severe thrombocytopenia was most commonly found in malaria followed by acute undifferentiated febrile illness (AUFI). In the study by Chakraverty et al., thrombocytopenia (platelet $<100,000 /$ cumm) was identified in $38 \%$ of the patients whereas severe thrombocytopenia (platelet $<50,000 /$ cumm) was observed in $12.5 \%$ of the patients. The most common causes of 


\begin{tabular}{|c|c|c|c|c|c|c|}
\hline \multirow{2}{*}{$\begin{array}{l}\text { Patients groups } \\
(n=200)\end{array}$} & \multirow{2}{*}{$\begin{array}{l}\text { Total patients } \\
\text { affected }\end{array}$} & \multicolumn{2}{|c|}{ Outcome } & \multicolumn{3}{|c|}{ Requirement of blood transfusion } \\
\hline & & Expired, $n(\%)$ & Survived, $n$ (\%) & Packed cells ( $n$ ) & $\operatorname{FFP}(n)$ & Platelet (n) \\
\hline Acute fulminant hepatitis & 31 & $16(51.60)$ & $15(48.40)$ & 11 & 30 & 3 \\
\hline Dengue & 33 & $17(51.50)$ & $16(48.50)$ & 3 & 5 & 17 \\
\hline HELLP syndrome & 3 & $2(66.70)$ & $1(33.30)$ & 3 & 3 & 3 \\
\hline ITP & 1 & 0 & $1(100)$ & 0 & 1 & 1 \\
\hline Leptospirosis & 30 & $21(70)$ & $9(30)$ & 7 & 8 & 11 \\
\hline Malignancy & 2 & $2(100)$ & $0(0)$ & 1 & 0 & 0 \\
\hline Malaria & 47 & $30(55.32)$ & $17(44.8)$ & 14 & 13 & 24 \\
\hline Sepsis & 14 & $12(85.70)$ & $2(14.30)$ & 5 & 8 & 7 \\
\hline Snake bite & 3 & $1(33.33)$ & $2(66.66)$ & 1 & 1 & 0 \\
\hline AUFI & 36 & $25(69.40)$ & $11(30.60)$ & 3 & 9 & 16 \\
\hline Total/percentage overall & 200 & $126(63.00)$ & $74(37.00)$ & $48 / 24$ & $78 / 39$ & $82 / 41.0$ \\
\hline
\end{tabular}

AUFI: Acute undifferentiated febrile illness; ITP: Idiopathic thrombocytopenic purpura; HELLP: Hemolysis; elevated liver enzymes levels; low platelet count levels; FFP: Fresh frozen plasma

\begin{tabular}{lcc}
\hline \multirow{2}{*}{$\begin{array}{l}\text { Table 5: Outcome of patients presenting with } \\
\text { thrombocytopenia (platelet }<\mathbf{1 0 0 , 0 0 0 / c u m m ) ~} \\
\text { of admission }\end{array}$} & \multicolumn{2}{c}{ Outcome } \\
\cline { 2 - 3 } $\begin{array}{l}\text { Thrombocytopenia } \\
\text { ( } \boldsymbol{n}=\mathbf{1 6 1 )}\end{array}$ & Expired & Survivors \\
\hline Acute fulminant hepatitis & 8 & 1 \\
Dengue & 17 & 12 \\
HELLP syndrome & 1 & 1 \\
ITP & 0 & 1 \\
Leptospirosis & 18 & 10 \\
Malignancy & 2 & 0 \\
Malaria & 25 & 20 \\
Sepsis & 5 & 4 \\
Snake bite & 1 & 1 \\
AUFI & 25 & 9 \\
Total & 102 & 59 \\
\hline$P<0.05$. AUFI: Acute undifferentiated febrile illness; ITP: Idiopathic \\
thrombocytopenic purpura; HELLP: Hemolysis; elevated liver enzymes \\
levels; low platelet count levels &
\end{tabular}

thrombocytopenia included DIC and dilution following blood transfusion. In $54 \%$ of the patients, the cause of thrombocytopenia was not identified. The mortality rate of patients who developed thrombocytopenia was significantly higher than in those who did not (32/85 vs. 27/139, $P<0.005) .{ }^{[4]}$

Baughman et al. showed that thrombocytopenia was associated with longer hospital stay $(P<0.001)$ and higher mortality $(P<0.001) \cdot{ }^{[13]}$ Analysis of association between platelet count, aPTT, PT/INR, and mean MICU stay was done using tests of significance; it showed that there is a significant association between thrombocytopenia and mean MICU stay $(P<0.05)$ as shown in Table 9. The highest mean duration of stay was seen in patients of sepsis, i.e., 8 days.

A prolonged global coagulation time - such as the PT or the aPTT - occurs in $14 \%-28 \%$ of intensive care patients. ${ }^{[8,14]}$ In our study, 94 patients (47\%) had an INR value $\geq 1.5-1.9$ followed by 62 patients ( $31 \%$ ) with an INR $<1.5$ and then 44 patients $(22 \%)$ with an INR $\geq 2$. Of 31 patients, $22(71 \%)$ patients with acute fulminant hepatitis had an INR $\geq 2$. Of 47 patients of malaria, $29(61.70 \%)$ had an INR $\geq 1.5$. In the study by Chakraverty et al., the PT ratio was $>1.5$ in $66.0 \%$ and $>2$ in $29.1 \%$. The most common causes of prolongation of PT were DIC in $12 \%$, liver failure in $10 \%$, and massive transfusion in $10 \%$. The cause of an elevated PT was not identified in $44 \% .{ }^{[4]}$

In our study, 106 patients (53\%) were observed to have an aPTT $<40 \mathrm{~s}$, followed by 84 patients $(42 \%)$ with an aPTT $\geq 40-59$ s and 10 patients ( $5 \%$ ) with an aPTT $>60$ s. In patients of acute fulminant hepatitis, 28/31 (90.32\%) had an aPTT $>40 \mathrm{~s}$. Severity analysis of patients admitted with hemostatic abnormalities in terms of deranged INR, aPTT, platelet count $<50,000 / \mathrm{cumm}$, and requirement of one of the blood products was done. There were 24 such patients who were admitted, of which 14 (58.3\%) expired and 10 (41.7\%) survived. Patients diagnosed with malaria $(n=8)$ formed the majority, of which five expired and three survived. There was a strong suspicion of DIC in the above group; hence, d-dimer levels, fibrinogen degradation products, and fibrinogen levels were only done in this group. Of 24 patients, $5(2.5 \%)$ patients were confirmed to have developed DIC. Among the five patients, one died of dengue and the other with leptospirosis. The three survivors were diagnosed with HELLP Syndrome pneumonia with sepsis, and AUFI, respectively. DIC is far less common, occurring is an estimated $1 \%$ of hospitalized patients, ${ }^{[15]}$ but it may occur in up to $50 \%$ of patients with severe sepsis. ${ }^{[16]}$

Of the patients studied, 107 (53.5\%) required mechanical ventilation. There were 85 patients $(42.5 \%)$ who developed acute respiratory distress syndrome (ARDS), of which 66 patients required mechanical ventilation and 19 patients were on noninvasive ventilation. Global disturbances of key homeostatic systems as in multiple organ system failure have also been associated with a higher incidence of 
Table 6: Various bleeding manifestations seen in patients, their outcome, and deranged laboratory parameters of patients admitted in the medical intensive care unit with hemostatic abnormalities

\begin{tabular}{|c|c|c|c|c|c|}
\hline \multirow{2}{*}{$\begin{array}{l}\text { Bleeding manifestation } \\
\text { and their sites }(n=200)\end{array}$} & \multicolumn{2}{|c|}{ Outcome } & \multirow{2}{*}{$\begin{array}{c}\text { Platelet } \\
<100,000 / \text { cumm }(n)\end{array}$} & \multirow{2}{*}{$\begin{array}{l}\text { Deranged aPTT } \\
(\geq 40 \mathrm{~s})(n)\end{array}$} & \multirow{2}{*}{$\begin{array}{c}\text { Deranged INR } \\
(\geq 1.5)(n)\end{array}$} \\
\hline & Expired $(n)$ & Survivors (n) & & & \\
\hline Bleeding at $\mathrm{CVC}$ site & 12 & 16 & 23 & 13 & 21 \\
\hline Subconjunctival hemorrhage & 24 & 14 & 36 & 17 & 17 \\
\hline Hemoptysis & 31 & 6 & 33 & 15 & 37 \\
\hline Hematuria & 39 & 23 & 42 & 35 & 46 \\
\hline Bleeding gums & 9 & 7 & 15 & 7 & 14 \\
\hline Epistaxis & 17 & 10 & 22 & 11 & 18 \\
\hline Purpura & 21 & 11 & 28 & 13 & 20 \\
\hline Melena & 12 & 8 & 16 & 10 & 13 \\
\hline Menorrhagia & 3 & 4 & 4 & 5 & 7 \\
\hline Hematemesis & 11 & 5 & 15 & 7 & 7 \\
\hline Bleeding PR & 3 & 5 & 5 & 4 & 6 \\
\hline
\end{tabular}

Total number of patients were 200, but patients had more than one bleeding manifestations as shown below. PR: Per rectum; aPTT: Activated partial thromboplastin time; INR: International normalized ratio; CVC: Central venous catheter

\begin{tabular}{|c|c|c|c|}
\hline Bleeding manifestations & $\begin{array}{l}\text { Packed } \\
\text { cells (\%) }\end{array}$ & FFP (\%) & Platelet (\%) \\
\hline Bleeding at CVC site & 14.2 & 28.57 & 39.28 \\
\hline Subconjunctival hemorrhage & 21.10 & 55.26 & 39.47 \\
\hline Hemoptysis & 10.81 & 21.62 & 29.72 \\
\hline Hematuria & 37.09 & 62.90 & 27.41 \\
\hline Gastrointestinal bleeding & 15.00 & 35.0 & 41.93 \\
\hline Epistaxis & 11.11 & 25.92 & 51.85 \\
\hline Purpura & 3.12 & 21.8 & 25.0 \\
\hline Menorrhagia/bleeding PV & 57.10 & 85.71 & 57.10 \\
\hline
\end{tabular}

coagulation disorders in ARDS nonsurvivors. The incidence of coagulopathies in patients with ARDS is $26 \%{ }^{[17,18]}$

Patients diagnosed with malaria formed the highest number of cases in our study, i.e., 47/200 (23.5\%), with predominantly young males affected. The factors responsible for the age pattern include outdoor work for young adult males and outdoor sleeping habits which make them more prone to mosquito bites. There were 12 patients with mixed malaria (25.53\%), 15 with Plasmodium falciparum malaria (31.91\%), and 20 patients with Plasmodium vivax malaria $(42.55 \%)$ in the MICU. The highest mortality was seen in patients with $P$. vivax malaria $13 / 30$ patients $(43.33 \%)$. The common bleeding manifestations that were seen in our study in patients with malaria were hemoptysis $(27.65 \%)$. Thrombocytopenia (platelet $<100,000 / \mathrm{cumm}$ ) was seen in 45/47 (95.74\%). Severe thrombocytopenia (platelet $<50,000 /$ cumm) was seen in $33 / 47$ patients, i.e., $70.21 \%$ of all patients with malaria, of which 19 died (57.57\%) and 14 (42.42\%) survived. A deranged INR ( $\geq 1.5)$ was observed in $61.7 \%$ and a deranged aPTT ( $\geq 40 \mathrm{~s}$ ) was observed in $38.3 \%$ of all malaria patients. In patients with $P$. falciparum, INR $(\geq 1.5)$ was seen in
$11 / 15$ patients, i.e., $73.33 \%$, and an aPTT ( $\geq 40 \mathrm{~s}$ ) was seen in $9 / 15$ patients, i.e., $60 \%$. These findings are concordant with a study by Misra et al. where prolonged aPTT (67\%) was seen in patients with $P$. falciparum. ${ }^{[19]}$ ARDS was seen in $26 / 47$ patients of malaria who were admitted to the MICU with bleeding manifestations, i.e., 55.31\%, in concordance with Gupta et al. where the prevalence of ARDS due to malaria was $21.4 \%$. ${ }^{[20]}$ The highest mortality was in P. vivax $10 / 15$ patients $(38.46 \%)$; these results are in concordance to the study by Limaye et al. where mortality due to ARDS was more in patients with $P$. vivax malaria. ${ }^{[21]}$

Of the 200 patients, 33 were diagnosed with dengue in whom gastrointestinal bleeding was predominant, i.e., 17/33, followed by petechiae (10 patients) and hematuria (8 patients). In our study, of 31 patients $(15.5 \%)$ of acute fulminant hepatitis, 21 were females, of which 12 patients $(57.14 \%)$ belonged to the obstetric group (pregnant and postpartum). Hematuria was the most common bleeding manifestation in patients with hepatitis. The major cause of fulminant hepatic failure was found to be hepatitis $E(48.3 \%)$, i.e. $15 / 31$ patients, the others being hepatitis $\mathrm{A}$, hepatitis $\mathrm{B}$, and rat kill poisoning, and in eight patients, the cause was undetermined. This is supported by the fact that hepatitis A and E are common causes of hepatic encephalopathy in developing countries as observed in studies by Acharya et al. ${ }^{[22]}$

In our study, sepsis formed $7 \%$ of the admissions that presented with bleeding manifestations. The mortality in these patients was $85.70 \%$. Thrombocytopenia was seen in $64.28 \%$. Similar findings were seen in the study by Brun-Buisson et al., ${ }^{[23]}$ where sepsis is a clear risk factor for thrombocytopenia, with an estimated incidence of 35\%-59\%. AUFI patients formed $18 \%$ of our admissions. There were three patients of snake bite who were admitted; hematuria was observed in the patient who succumbed. One of the survivors had epistaxis and the other one had hematemesis and local bleeding. There were two patients with malignancy. The first patient was a case 
of chronic myeloid leukemia who presented with hematuria, gastrointestinal bleeding, and epistaxis. The second patient was a case of acute myeloid leukemia-M4 who presented hematuria.

Of the study population, 48 patients $(24 \%)$ received packed cells, 78 patients $(39 \%)$ received fresh frozen plasma (FFP), and 82 patients $(41 \%)$ received platelets. Hematuria was the most common bleeding manifestation seen in 62 patients and 39 of them required FFP (62.90\%). Platelet requirement was the highest in those with bleeding per vaginum/ menorrhagia $(57.10 \%)$ followed by $51.85 \%$ of patients with epistaxis. The indications for transfusion were hemorrhage,

\begin{tabular}{|c|c|c|c|}
\hline & Chakraverty et al. & Arnold et al. & Our study \\
\hline Cardiovascular & $34 \%$ & $15 \%$ & $0 \%$ \\
\hline Gastrointestinal & $17 \%$ & $28 \%$ & $0 \%$ \\
\hline Trauma & $12 \%$ & $0 \%$ & $0 \%$ \\
\hline Respiratory & $9 \%$ & $19 \%$ & $0 \%$ \\
\hline Neurological & $7 \%$ & $4 \%$ & $0 \%$ \\
\hline Hepatic & $3 \%$ & $0 \%$ & $15.5 \%$ \\
\hline Oncology & $3 \%$ & $0 \%$ & $1 \%$ \\
\hline Renal & $2 \%$ & $6 \%$ & $0 \%$ \\
\hline Obstetric & $2 \%$ & $0 \%$ & $1.5 \%$ \\
\hline Hematologic & $0 \%$ & $1 \%$ & $0.5 \%$ \\
\hline Sepsis & $0 \%$ & $13 \%$ & $7 \%$ \\
\hline Metabolic & $0 \%$ & $8 \%$ & $0 \%$ \\
\hline Urological & $2 \%$ & $0 \%$ & $23.5 \%$ \\
\hline Malaria & $0 \%$ & $0 \%$ & $18 \%$ \\
\hline AUFI & $0 \%$ & $0 \%$ & $16.5 \%$ \\
\hline Dengue & $0 \%$ & $0 \%$ & $15 \%$ \\
\hline Leptospirosis & $0 \%$ & $0 \%$ & $15 \%$ \\
\hline Snake bite & $0 \%$ & $0 \%$ & $1.5 \%$ \\
\hline Miscellaneous & $10 \%$ & $6 \%$ & $0 \%$ \\
\hline
\end{tabular}

\begin{tabular}{|c|c|c|c|}
\hline Variable & $n$ & $\begin{array}{c}\text { Mean MICU stay } \pm \text { SD } \\
\text { (Days) }\end{array}$ & $P$ \\
\hline \multicolumn{4}{|c|}{ Platelet $<100,000 /$ cumm } \\
\hline No & 39 & $4.97 \pm 4.6$ & $<0.05$ \\
\hline Yes & 161 & $3.53 \pm 3.1$ & \\
\hline \multicolumn{4}{|c|}{ Deranged PT/INR $(\geq 1.5)$} \\
\hline No & 138 & $4.04 \pm 3.6$ & 0.17 \\
\hline Yes & 62 & $3.31 \pm 3.17$ & \\
\hline \multicolumn{4}{|c|}{ Deranged aPTT $(\geq 40)$} \\
\hline Yes & 94 & $4 \pm 3.6$ & 0.47 \\
\hline No & 106 & $3.64 \pm 3.4$ & \\
\hline
\end{tabular}

MICU: Medical intensive care unit; SD: Standard deviation; PT: Prothrombin time; INR: International normalized ratio; aPTT: Activated partial thromboplastin time low platelet counts, prolonged PT or to provide cover for invasive intervention. Our results are consistent with the study done by Lauzier et al., where the FFP transfusion requirement in critically ill patients was $29.9 \%$. $^{[24]}$ Patients with acute fulminant hepatitis were observed to require more number of packed cells transfusion (35.5\%) and FFP transfusion in comparison to the other patients who were admitted. Platelet requirement was similar in patients with malaria and dengue $(51 \%)$.

In a study by Rao et al., where blood component use in critically ill patients was studied, 53\% patients were administered red cells, $16 \%$ were administered platelets, and $22 \%$ of the patients were transfused FFP. ${ }^{[25]}$

In our study, APACHE II score was found to be a good predictor of blood transfusion requirements as interpreted by the ROC curves (area under the curve $=0.63, P<0.05$ ) and was statistically significant as shown in Table 10 and Figure 1.

The overall MICU mortality was 37.95\% (574/1515). Out of 200 patients who were admitted with bleeding manifestations, 126 expired (63\%) and 74 (37\%) survived. In a study by Chakraverty et al., the overall MICU mortality was $27.2 \%$, i.e., $64 / 235$ patients died, and of the 32 patients who had clinically evident bleeding 13 patients expired. ${ }^{[4]}$

\section{Conclusions}

Our study shows that a significant number of patients present with hemostatic abnormalities in the MICU with predominantly tropical diseases such as malaria, dengue, and leptospirosis. A high APACHE II score predicts a higher blood transfusion requirement. Thrombocytopenia is an important marker to predict mortality and also has a significant association with MICU stay. Management of bleeding and coagulopathies in the MICU should be directed at treating the underlying condition and avoiding the correction of laboratory abnormalities with blood products unless there is a clinical bleeding problem, a

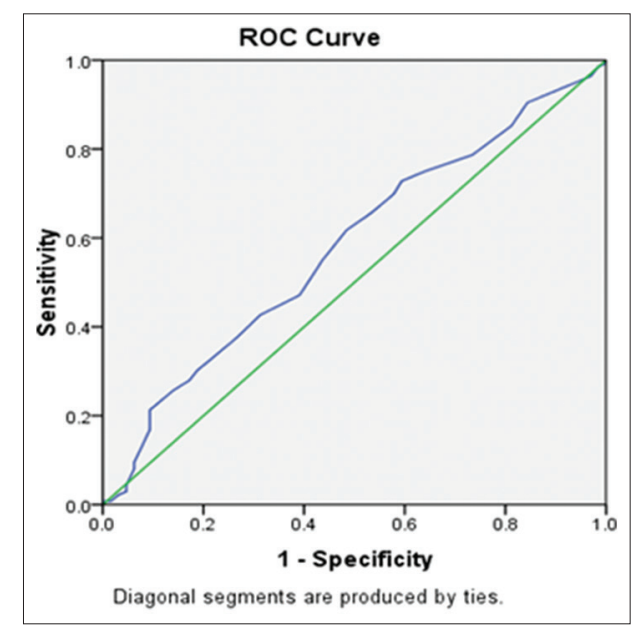

Figure 1: Receiver operating characteristic curve demonstrating the relationship between acute Physiology and Chronic Health Evaluation II score and requirement of blood products for transfusion 


\section{Table 10: Demonstration of relationship between Acute Physiology and Chronic Health Evaluation II score and requirement of blood products for transfusion}

\begin{tabular}{|c|c|c|c|c|}
\hline \multicolumn{5}{|c|}{ AUC } \\
\hline \multicolumn{3}{|c|}{$\begin{array}{l}\text { Test result variable(s): APACHE II } \\
\text { score }\end{array}$} & \multicolumn{2}{|c|}{ Asymptotic 95\% Cl } \\
\hline AUC & SE & Asymptotic significant & Lower bound & Upper bound \\
\hline 0.63 & 0.043 & $<0.05$ & 0.526 & 0.684 \\
\hline
\end{tabular}

surgical procedure is required, or both. ${ }^{[20,23]}$ Clinically evident bleeding in patients requires prompt diagnosis, intensive monitoring, and early therapeutic intervention. We would like to draw attention to the need for further studies in the Indian setup that focuses on diseases that are prevalent here that present with bleeding and coagulopathy so as to be able to frame rational transfusion policies that would guide management of bleeding and coagulopathies in the MICU.

\section{Financial support and sponsorship}

Nil.

\section{Conflicts of interest}

There are no conflicts of interest.

\section{References}

1. Collins English Dictionary - Complete \& Unabridged. $10^{\text {th }}$ ed. 2010.

2. Rice TW, Wheeler AP. Coagulopathy in critically ill patients: Part 1: Platelet disorders. Chest 2009;136:1622-30.

3. Wheeler AP, Rice TW. Coagulopathy in critically ill patients: Part 2-soluble clotting factors and hemostatic testing. Chest 2010;137:185-94.

4. Chakraverty R, Davidson S, Peggs K, Stross P, Garrard C, Littlewood TJ, et al. The incidence and cause of coagulopathies in an intensive care population. Br J Haematol 1996;93:460-3.

5. Trey C, Davidson CS. The management of fulminant hepatic failure. Prog Liver Dis 1970;3:282-98.

6. Levy MM, Fink MP, Marshall JC, Abraham E, Angus D, Cook D, et al. $2001 \mathrm{SCCM} / \mathrm{ESICM} / \mathrm{ACCP} / \mathrm{ATS} / \mathrm{SIS}$ international sepsis definitions conference. Crit Care Med 2003;31:1250-6.

7. Phuong HL, de Vries PJ, Nagelkerke N, Giao PT, Hung le Q, Binh TQ, et al. Acute undifferentiated fever in Binh Thuan Province, Vietnam: Imprecise clinical diagnosis and irrational pharmaco-therapy. Trop Med Int Health 2006;11:869-79.

8. Arnold DM, Donahoe L, Clarke FJ, Tkaczyk AJ, Heels-Ansdell D,
Zytaruk N, et al. Bleeding during critical illness: A prospective cohort study using a new measurement tool. Clin Invest Med 2007;30:E93-102.

9. Mercer KW, Gail Macik B, Williams ME. Hematologic disorders in critically ill patients. Semin Respir Crit Care Med 2006;27:286-96.

10. Strauss R, Wehler M, Mehler K, Kreutzer D, Koebnick C, Hahn EG, et al. Thrombocytopenia in patients in the medical Intensive Care Unit: Bleeding prevalence, transfusion requirements, and outcome. Crit Care Med 2002;30:1765-71.

11. Vanderschueren S, De Weerdt A, Malbrain M, Vankersschaever D, Frans E, Wilmer A, et al. Thrombocytopenia and prognosis in intensive care. Crit Care Med 2000;28:1871-6.

12. Sharma B, Sharma M, Majumder M, Steier W, Sangal A, Kalawar M, et al. Thrombocytopenia in septic shock patients - A prospective observational study of incidence, risk factors and correlation with clinical outcome. Anaesth Intensive Care 2007;35:874-80.

13. Baughman RP, Lower EE, Flessa HC, Tollerud DJ. Thrombocytopenia in the Intensive Care Unit. Chest 1993;104:1243-7.

14. Levi M, Opal SM. Coagulation abnormalities in critically ill patients. Crit Care 2006;10:222.

15. Matsuda T. Clinical aspects of DIC - Disseminated intravascular coagulation. Pol J Pharmacol 1996;48:73-5.

16. Levi M, Toh CH, Thachil J, Watson HG. Guidelines for the diagnosis and management of disseminated intravascular coagulation British Committee for Standards in Haematology. Br J Haematol 2009;145:24-33

17. Hasegawa N, Husari AW, Hart WT, Kandra TG, Raffin TA. Role of the coagulation system in ARDS. Chest 1994;105:268-77.

18. Dorinsky PM, Gadek JE. Mechanisms of multiple nonpulmonary organ failure in ARDS. Chest 1989;96:885-92.

19. Misra DP, Das S, Pattnaik M, Singh SC, Jena RK. Relationship of hepatic and renal dysfunction with haemorrheological parameters in Plasmodium falciparum malaria. J Assoc Physicians India 2011:59:552-6.

20. Gupta D, Ramanathan RP, Aggarwal AN, Jindal SK. Assessment of factors predicting outcome of acute respiratory distress syndrome in North India. Respirology 2001;6:125-30.

21. Limaye CS, Londhey VA, Nabar ST. The study of complications of vivax malaria in comparison with falciparum malaria in Mumbai J Assoc Physicians India 2012;60:15-8.

22. Acharya SK, Dasarathy S, Kumer TL, Sushma S, Prasanna KS, TandonA, et al. Fulminant hepatitis in a tropical population: Clinical course, cause, and early predictors of outcome. Hepatology 1996;23:1448-55.

23. Brun-Buisson C, Doyon F, Carlet J, Dellamonica P, Gouin F, Lepoutre A, et al. Incidence, risk factors, and outcome of severe sepsis and septic shock in adults. A multicenter prospective study in Intensive Care Units. French ICU Group for Severe Sepsis. JAMA 1995;274:968-74.

24. Lauzier F, Cook D, Griffith L, Upton J, Crowther M. Fresh frozen plasma transfusion in critically ill patients. Crit Care Med 2007;35:1655-9.

25. Rao MP, Boralessa H, Morgan C, Soni N, Goldhill DR, Brett SJ, et al. Blood component use in critically ill patients. Anaesthesia 2002;57:530-4. 